\title{
EFFECT OF HEALTH EDUCATION ON ADOLESCENT GIRLS REGARDING KNOWLEDGE ABOUT MENSTRUATION
}

\author{
Usha Rani Chadalawadaํ, Aruna Devi $S^{2}$, Sandhya Rani $M^{3}$
}

1 Professor, Department of Community Medicine, Government Siddhartha Medical College, Vijayawada.

${ }^{2}$ Senior Resident, Department of Community Medicine, Government Siddhartha Medical College, Vijayawada.

${ }^{3}$ Postgraduate Student, Department of Community Medicine, Government Siddhartha Medical College, Vijayawada.

ABSTRACT

\section{BACKGROUND}

According to the World Health Organization (WHO), adolescents are individuals aged between 10-19 years. In India, by 18 years $54 \%$ adolescents are married, $25-35 \%$ of adolescent girls of about 17 years of age begin child bearing and these adolescent pregnancies constitute $10-15 \%$ of total pregnancies. In India, although abortion is legal, unsafe abortions account for $50 \%$ of all maternal deaths of girls between 15 and 19 years. Most of the health problems in adolescents need personal, friendly, and confidential advices and reassurances from the medical personnel, to get clear insight into the health problems with a little medical intervention. Family Life Education for adolescents about current needs associated with changing physical, cognitive, social, emotional, and sexual developments promote them to fulfil their anticipatory or future family-related needs by preparing them for adult roles to meet responsibilities in marriage and parenting.

Aim- To know the extent of improvement of knowledge on menstruation and menstrual hygiene practices amongst school going adolescent girls in a village in Krishna District after educational Intervention.

Objective- To assess the basal knowledge about menstruation among school going adolescent girls and to assess the impact of Reproductive Health Education with a special emphasis on Nutrition and Reproductive Health.

\section{MATERIALS AND METHODS}

The study is done on 250 adolescent girls of Zilla Parishad High School of Nidamanuru village, coming under the Primary Health Centre area of Kankipadu, Krishna District Andhra Pradesh.

\section{RESULTS}

Interventional study was conducted among 250 adolescent high school girls. Out of 250 students, majority were in the age group of 13-14 years (76\%). Two thirds of study subjects were Hindus. Majority of the study subjects belong to backward caste. Mothers of $35.38 \%$ and $32.05 \%$ girls had primary or secondary educational status. Majority (42.61\%) of the study subjects belong to class IV, modified B. G. Prasad's socioeconomic status followed by class III (28.14\%) followed by class II (24.3\%).

\section{CONCLUSION}

Knowledge regarding various aspects of menstruation was poor before educational intervention which subsequently improved after providing health education. Therefore, family life education should be strictly implemented in the school and college curriculum with age appropriate topics which include package of information regarding small family norm, gender discrimination, domestic violence, nutrition, pubertal changes, menstrual hygiene, pregnancy, abortion, contraception, unsafe sex, HIV/AIDS, etc.

\section{KEYWORDS}

Adolescent Girl, Menstruation, Educational Intervention.

HOW TO CITE THIS ARTICLE: Chadalawada UR, Devi AS, Rani SM. Effect of health education on adolescent girls regarding knowledge about menstruation. J. Evolution Med. Dent. Sci. 2017;6(13):1040-1043, DOI: 10.14260/Jemds/2017/223

\section{BACKGROUND}

Adolescent girls constitute $1 / 5$ th of the total world female population and 14 million adolescent girls deliver every year, account for $11 \%$ of all births worldwide. [1,2] They account for $23 \%$ of the overall burden of disease (Disability-adjusted life years) due to pregnancy and childbirth.[3] They are a vulnerable group, particularly in developing countries where female child is neglected. An estimated 16 million are girls

Financial or Other, Competing Interest: None.

Submission 30-05-2016, Peer Review 25-01-2017,

Acceptance 03-02-2017, Published 13-02-2017.

Corresponding Author:

Dr. Usha Rani Chadalawada,

Professor PSM/Community Medicine,

Department of Community Medicine,

Government Siddhartha Medical College,

Vijayawada-520008.

E-mail: dr.usha1@gmail.com

DOI: $10.14260 /$ jemds $/ 2017 / 223$

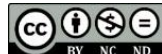

aged 15-19 years and the youngest mothers are the most likely to experience complications and die of pregnancy related causes.[4] Adolescent girls need accessibility to information and education regarding services related to Nutrition, Reproductive Health, Family Planning, and General Health. Programmes can reach the girls through a variety of channels like Schools, Youth-Oriented Health Programmes, Workplaces, Marriage Registration Systems, etc. Schools can play a key part to help the adolescent girls to become healthy adults. Research shows that promoting female education and literacy can improve nutrition and encourage females to seek regular health care. Ensuring that adolescent girls receive enough food, iron and foliate supplements and iodinefortified foods, along with delay in their first pregnancy will protect them from sexually transmitted infections and other diseases which can help girls become healthy women. Teaching girls to improve knowledge regarding nutrition, cooking methods and food handling techniques to promote their own health and family health should be a part of the 
education system. Healthy, educated, adolescent girls play a key role to reduce poverty by attaining economic empowerment and by procuring healthy generations.

The current study is aimed to assess the baseline knowledge about menstruation among school going adolescent girls, and to assess the impact of reproductive health education with a special emphasis on nutrition and reproductive health.

\section{MATERIALS AND METHODS}

It is a cross-sectional observational study taken up in Nidamanuru village, was selected by simple random technique (by lottery method), Nidamanuru comes under the primary health centre area of Kankipadu. List of the Government high schools was obtained from the District Educational Officer (DEO). As there is only one Government High School in Nidamanuru village, i.e. Zilla Parishad High School, it was selected for the study. The study population constitutes adolescent girls (10-19 years) of Zilla Parishad High School.

Sample size is calculated as per $(\mathrm{n})=4 \mathrm{pq} / \mathrm{l} 2$ where $\mathrm{p}=66 \%, \mathrm{q}=34 \%$ and $\mathrm{l}=10 \%$ of $\mathrm{p}$,

So $\mathrm{n}=206$. However, sample size of 250 school going adolescent girls was taken.

In the selected high school, according to the Registers, a total number of 602 girls was in the age group of 11-16 years, from the 602 excluding the 10th class students for academic purpose, 541 girls were selected and numbered. By using systematic random technique based on the strength every second girl was selected for the study until the sample size of 250 was met. If any selected girl was found to be absent at the time of data collection, a second visit was made on the next day. If the girl was absent even after the second visit, adjacent girl was taken for the study.

They were divided into 8 batches, each batch consisting 31-33 students. In the pre-test, a predesigned semistructured, pretested schedule in local language was used for personal interview for each batch in school working hours.

After pre-test, educational intervention has been conducted for 4 months, for each batch, every day one hour class was taken by using chalk and board, posters, charts, flip charts and video clips. After one month of intervention, post- test was conducted by using the same questionnaire which was used in the pre-test.

\section{The following Inclusion and Exclusion Criteria have been considered}

Inclusion criteria includes all adolescent girls aged 11-16 years at Nidamanuru village, willing to participate, available at the time of data collection, and irrespective of attainment of menarchial age.

Exclusion criteria includes high school girls in age group of $<11$ years $\&>16$ years, who are not available at the time of data collection, and who are not willing to participate in the study.

The informed consent has been taken from the adolescent girls after explaining the purpose of the study.

Prior institutional ethical committee approval has been taken before proceeding for collection of data.

\section{RESULTS}

\begin{tabular}{|c|c|c|}
\hline $\begin{array}{c}\text { Sociodemographic } \\
\text { Variable }\end{array}$ & Number & Percentage \\
\hline Age of the Students & 20 & 8 \\
$11-12$ & 190 & 76 \\
$13-14$ & 40 & 16 \\
$15-16$ & & \\
Region & 162 & 64.8 \\
Hindus & 63 & 25.2 \\
Christians & 25 & 10.0 \\
Muslims & & \\
Mothers Education & 70 & 28 \\
Illiterates & 89 & 35.6 \\
Primary & 82 & 32.8 \\
Secondary & 7 & 2.8 \\
Intermediate & 2 & 0.8 \\
Graduate & & \\
Socio-Economic Status & 1 & 0.69 \\
I & 55 & 21.43 \\
Il & 69 & 28.14 \\
III & 109 & 42.61 \\
IV & 16 & 7.12 \\
\hline
\end{tabular}

Table 1. Sociodemographic Profile of the Students $(n=250)$

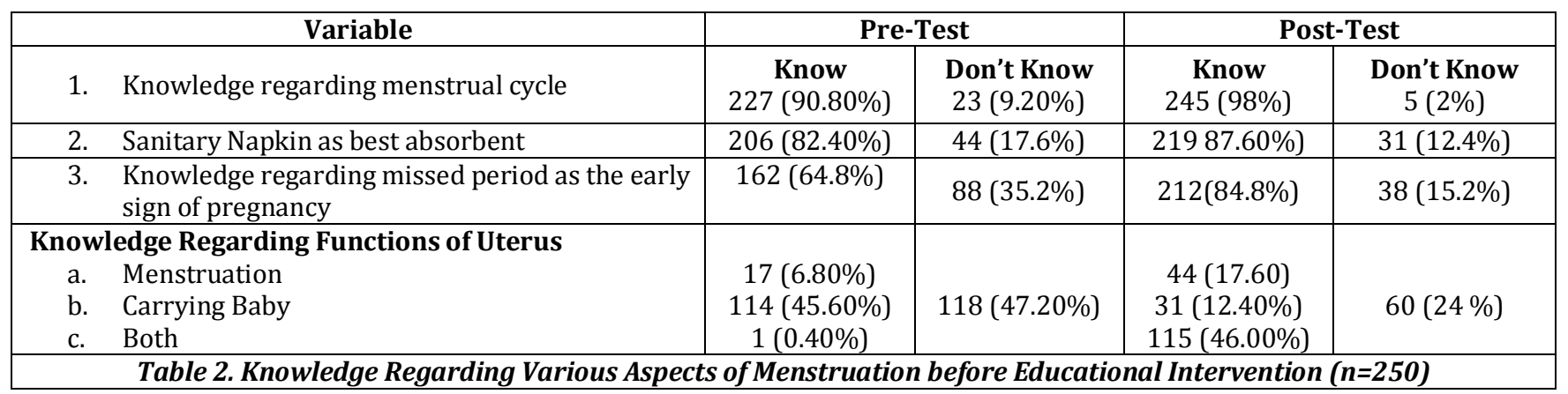

- Among 250 study subjects, 227 (90.8\%) had knowledge regarding menstrual cycle and $23(9.2 \%)$ were unaware of it before intervention.

- Knowledge regarding menstrual cycle improved from $90.80 \%$ to $98 \%$ through interventional education which is statistically significant, as shown in the following figure. 


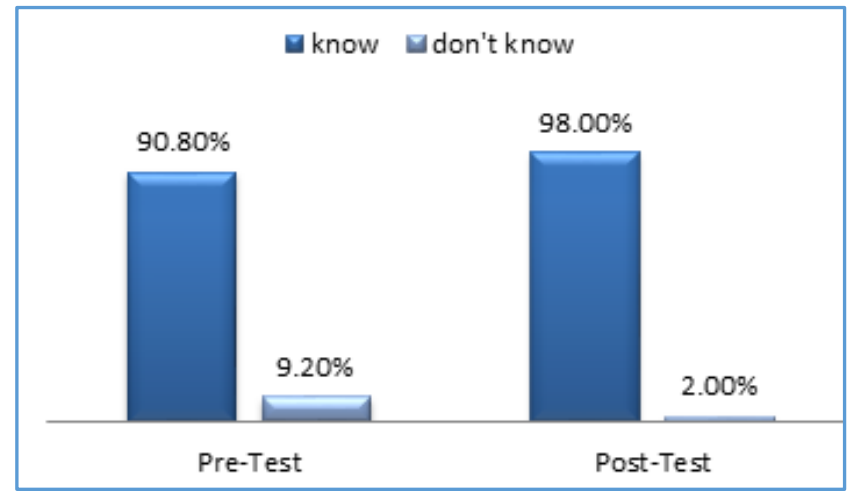

Chi-Square $=12.25 \quad \mathrm{df}=1 \mathrm{P}<0.05 . \quad$ Significant

\section{Figure 1. Pre-test and Post-test Percentages of Knowledge Regarding Menstrual Cycle}

Among 250 study subjects, 206 (82.4\%) had knowledge about sanitary napkin as best absorbent for menstrual blood flow and $12(4.8 \%)$ were of the idea that cloth is the best absorbent before intervention.

Knowledge regarding sanitary napkin as best absorbent for menstrual blood flow improved from $82.40 \%$ to $87.60 \%$ after educational intervention which is statistically not significant.

Among 250 girls, $1(0.40 \%)$ had knowledge regarding both functions of uterus i.e., for Menstruation and Carrying of the Baby and 118 (47.20\%) were unaware about it before intervention.

Knowledge regarding functions of uterus increased from $0.40 \%$ to $46.00 \%$ through educational intervention which is statistically significant. (Fig. 2).

menstruation $\square$ pregnancy $\square$ both $\square$ don't know

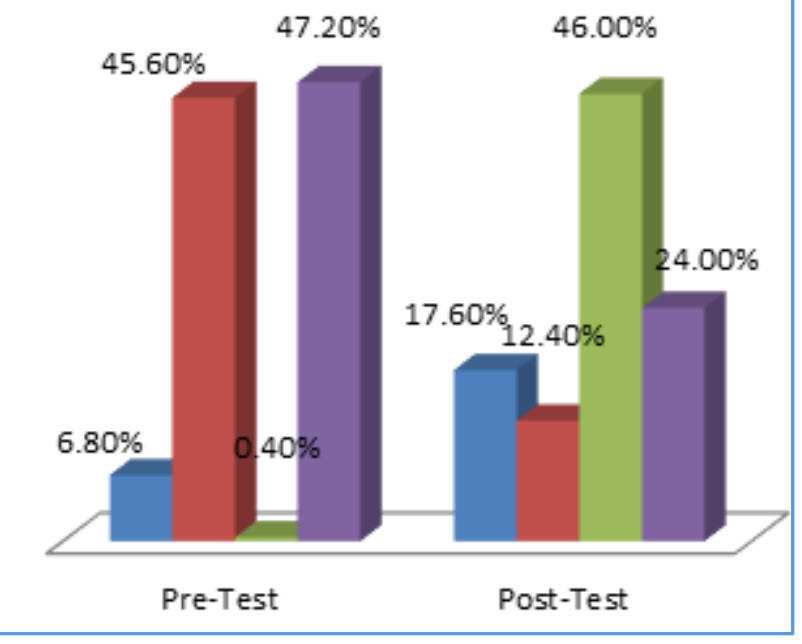

Chi- Square $=247.42 \mathrm{df}=3 \mathrm{P}<0.0001 \quad$ Significant

Figure 2. Shows Knowledge Regarding Functions of Uterus

\section{DISCUSSION}

This study evaluated the effect of health education by health professionals on adolescent girls' knowledge and attitudes towards reproductive health. Remarkable improvement was seen in relation with knowledge of participants about menstruation.
Various studies have shown the effectiveness of intervention in increasing the knowledge of reproductive health.

In the present study, majority of the girls were in the age group of 13-14 years, mean age of study subjects being $13.67 \pm 0.90$ years.

In our study, $90.80 \%$ girls had knowledge regarding menstrual cycle in the pre-test and it improved to $98.00 \%$ in the post-test, which is in accordance with an interventional study by R. S. P. Rao et al[5] where it improved from $77.2 \%$ to 95.6\% after intervention. As per the Report of Population Council and CARE India,[6,7] 39\% of boys and $97 \%$ of girls were found to be familiar with the menstrual cycle. In a study by $\mathrm{K}$. Malleshappa et al,[8] it improved significantly from $78.3 \%$ to $96.4 \%$.

In the present study, knowledge regarding best absorbent for menstrual blood flow improved from $82.40 \%$ to $87.60 \%$ after educational intervention. Above result is in consensus with Verma et al 29 study, on knowledge and practices about menstrual hygiene among higher secondary school girls in Varanasi district, in which $92.5 \%$ of girls were aware that sanitary napkin is best absorbent for menstrual blood.

In a cross sectional study by Prateek S. Bobhate et al, ${ }^{[9]}$ on Knowledge and Practices about Reproductive Health among Female Adolescents in An Urban Slum of Mumbai, 72.2\% of the subjects knew that sanitary pads should be used during menstruation. In a community-based cross-sectional observational study on menstrual hygienic practices, by $\mathrm{A}$ Dasgupta, M Sarkar,[10,11] 18 (11.25\%) girls used sanitary pads during menstruation.

In the present study, knowledge regarding missed period as early sign of pregnancy increased from $62.40 \%$ to $76.40 \%$ after educational intervention.

In a study by Priyanka Mukhopadhyay et al,[12] this knowledge increased from $42.1 \%$ to $95.8 \%$, in Parwej Saroj et al[13] study, it improved from $59 \%$ to $95 \%$ in conventional group and $63 \%$ to $96 \%$ in peer education group, $74.2 \%$ of participants were aware about missed period as the first sign of pregnancy. $40 \%$ of students were not aware of missed period as the first sign of pregnancy in R. S. P. Rao et al[5,11] study.

\section{CONCLUSION}

A comprehensive adolescent reproductive health program can provide right information at right age. Teachers in schools and colleges often find it difficult to discuss the topics related with reproduction.

It is commonly observed that they ask students to read these topics on their own from the text book. They are often unable to break the barrier of hesitation. Parents' position in this regard is more sensitive. They also lack the confidence and skills to address the psychosocial and sexuality related problems of adolescents.

This can be achieved through special educational programs (planned teaching program) in school curriculum, along with the involvement of parents, teachers \& health care providers.

Research should be done to assess the basal knowledge regarding family life education among different age groups in different settings in both males and females and to find out the kind of services needed by them so that interventions can be planned accordingly. 


\section{Recommendations}

School is a priority setting to target adolescents because it offers substantial opportunities for prevention. Health education regarding reproductive cycle, hygiene and nutrition should be incorporated in the school curriculum. Planned teaching program can be organised in school involving parents, teachers \& health care providers. Providing necessary materials like sanitary napkins, soaps and oil etc., with regular supervision will help in sustaining the knowledge gained thus far and further implementing hygienic practices. Iron and Folic acid supplementation and deworming also must be done periodically and consistently. All the current IEC activities should focus on dietary practices of adolescent girls in terms of increasing the intake of iron rich foods, as well as foods which promote the absorption of dietary iron. Regular periodic medical examination backed by good referral services and haemoglobin estimation, through conducting health camps involving specialists especially gynaecologists should be conducted.

\section{Strengths}

- $\quad$ This was a confined study pertaining to absolute health priority of adolescent girls.

- Knowledge regarding menstrual hygiene and reproductive system of women is well received and comprehended.

\section{Limitations of the Study}

The study was limited to rural adolescent girls from a selected high school. This study included only high school adolescent girls, hence college going adolescents were not studied.

The non-school going adolescents were not included in the study.

\section{REFERENCES}

[1] World Health Organization. Adolescent friendly health services-an agenda for change. Geneva: WHO 2002:3-5.

[2] UNICEF-Progress for Children A report card on adolescents Number 10, April 2012. Available from www.unicef org/lac/PFC2012.
[3] International Institute of Population Sciences (IIPS), 2000. National Family Health Survey (NFHS-2), India, 2000.

[4] United National Population Fund CST for CASA. Kathmandu, Nepal: The South Asia Conference on Adolescents 1999.

[5] Rao RS, Lena A, Nair NS, et al, Effectiveness of reproductive health education among rural adolescent girls: a school based intervention study in Udupi Taluk, Karnataka. Indian J Med Sci 2008;62(11):439-43.

[6] The population council's FRONTIERS in reproductive health programme and policy research division. Population Council and CARE India, 2002.

[7] Bhaskara RT, Usha RC. Textbook of Community Medicine. 3rd edn. Hyderabad: Paras Medical Publisher 2015.

[8] Malleshappa K, Krishna S, Nandini C. Knowledge and attitude about reproductive health among rural adolescent girls in Kuppam Mandal: an intervention study. Indmedica Biomedical Research 2011;22(3).

[9] Bobhate P, Shrivastava S. A cross sectional study of knowledge and practices about reproductive health among female adolescents in an urban slum of Mumbai. Journal of Family and Reproductive Health 2011;5(4):117-24.

[10] Dasgupta A, Sarkar M. Menstrual hygiene: how hygienic is the adolescent girl? Indian J Community Med 2008;33(2):77-80.

[11] Usha RC, Santhi KP. Assessment of menstrual hygiene practices among adolescent girls. SMJ 2016;3(1):13-16.

[12] Mukhopadhyay P, Paul B. An educational intervention study on improving awareness regarding some reproductive health issues among female school going adolescents. Indian Journal of Preventive and Social Medicine 2009;40(1-2):74-6.

[13] Parwej, Kumar R, Walia I, et al. Reproductive health education intervention trial. Indian $\mathrm{J}$ Pediatr 2005;72(4):287-91. 